\title{
Celebrating the collaboration of Bioanalysis and Bioanalysis Zone
}

Naamah Maundrell*,1

${ }^{1}$ Future Science Group, Unitec House, 2 Albert Place, London N3 1QB, UK

*Author for correspondence: Tel.: +44 0208371 6090; n.maundrell@bioanalysis-zone.com

\author{
"With our dedicated Editorial Board and Zone Leaders we hope to continue to bring the \\ bioanalytical community the most up-to-date content and also maintain the high scientific \\ standing."
}

First draft submitted: 12 December 2018; Accepted for publication: 21 February 2019; Published online: 4 April 2019

Keywords: bioanalysis $\bullet$ bioanalysis zone $\bullet$ collaboration $\bullet$ digital

As Bioanalysis celebrates its 10th anniversary, I reflect upon the partnership between the Journal [1] and the Zone [2], and how through working collaboratively, both have been at the forefront of bioanalytical advancements over the last 10 years.

\section{The Bioanalysis-Bioanalysis Zone relationship}

After Bioanalysis was established in 2009, thoughts turned toward the development of a sister site that would enhance the work and research published in the journal. Bioanalysis Zone was created in 2011 with a mission to advance the field of bioanalysis by increasing subject understanding and the sharing of knowledge across barriers to unite the bioanalytical community. The online platform is uniquely positioned to connect the rigorous research published in Bioanalysis with more interactive features. Currently, Bioanalysis Zone provides a range of resources including: news, interviews, commentaries, webinars, Spotlights, awards and an Education Zone.

With the advance of digital technology, Bioanalysis Zone has embraced digital developments to bring the latest bioanalytical topics to a wider audience. Through the use of social media, in particular, both the journal and the Zone are able to share and react to key developments, articles and news as and when they happen. Key social media platforms, such as Twitter, Facebook and LinkedIn, have enabled the bioanalytical community to be connected unlike ever before, which is a trend that we see continuing in the future.

\section{Key collaborations through the years}

Since Bioanalysis Zone's launch, we have evolved steadily with the Journal-Zone partnership continuing to develop and adapt. The work of both, Bioanalysis and Bioanalysis Zone, stems from a genuine passion to support and collaborate with the bioanalytical community. Fundamentally, we want to see the work of new techniques and methods that can directly help patients and advance the treatment for disease.

In order to achieve this we aim to deliver essential information in concise and accessible formats. On Bioanalysis Zone we host a variety of different content styles to suit both bioanalytical beginners and experts alike. Key Bioanalysis articles are also available to access for free, in the hope that through sharing research and ideas we can encourage scientists to communicate and collaborate further.

Over the last few years Bioanalysis and Bioanalysis Zone have collaborated on a number of projects. Panel discussions are a successful feature where the filmed content is hosted on the Zone and the written report published in the journal. The panel discussion series has enabled us to work with a variety of key opinion leaders and to gain perspective from CROs, pharma, vendors and academics on bioanalytical hot topics. We have thoroughly enjoyed bringing together different experts, companies and industries, whose path may not have crossed, to discuss the bioanalytical field. 
Furthermore, we have collaborated on joint publications including: The Bioanalysis Glossary, an essential resource which hosts over 400 terms; The Collectables: A Year in Bioanalysis, a special supplement providing key highlights from Bioanalysis Zone and Bioanalysis over the last year; and awards. We also try to align our Special Focus Issues and Spotlights to ensure we showcase the latest research, methods and techniques. Through hosting awards we have been able to showcase new talent and recognize the achievements of bioanalytical experts. Both the Bioanalysis Rising Star Award and the Bioanalysis Outstanding Contribution Award enable the opportunity of exposure and allow us to celebrate the great accomplishments of this field.

Conferences have been vital in expanding our knowledge and developing partnerships. Over the few years it has been wonderful to get to know the bioanalytical community, reaching out to new audiences and seeing familiar faces again. Both Bioanalysis and Bioanalysis Zone conference reports provide up-to-date information on key note talks, reporting back on challenges facing the community.

\section{9 \& beyond}

The field of bioanalysis is continually adapting with new modalities creating new challenges for the community. With our dedicated Editorial Board and Zone Leaders we hope to continue to bring the bioanalytical community the most up-to-date content and also maintain the high scientific standing. We are delighted to have reached this milestone birthday and would like to take this opportunity to thank all of you for your support and contributions over the years. May our collaborations continue to advance science!

Financial \& competing interests disclosure

N Maundrell is an employee of Future Science Group. The author has no other relevant affiliations or financial involvement with any organization or entity with a financial interest in or financial conflict with the subject matter or materials discussed in the manuscript apart from those disclosed.

No writing assistance was utilized in the production of this manuscript.

\section{References}

1. Bioanalysis - the Journal. https://www.future-science.com/journal/bio

2. Bioanalysis Zone. https://www.bioanalysis-zone.com/ 